\title{
Использование реестра проектных обязательств для формирования бюджета проекта
}

\author{
Грошева Н.Б. ${ }^{29}$
}

При управлении финансами проекта часто используют типовые бюджетные формы с шагом планирования в квартал. Этого недостаточно, так как бюджет не отражает точки заказа финансовых ресурсов и не закрепляет суммы за конкретными работами. Для эффективного планирования необходимо использовать дополнительные формы, одна из которых предлагается автором.

$J E L:$

Ключевые слова: управление затратами проекта, структура декомпозиции работ, реестр проектных обязательств

Важным инструментом управления проектом является управление его финансами.

Как правило, в компаниях ведутся специализированные формы по планированию и учету расходов, в том числе используют реестр договоров и кассовый план. Эти формы ориентированы на анализ контрагентов, балансирование притоков и оттоков денежных средств и используются для оперативного учета.

При бюджетировании проектов схема управления финансовыми потоками несколько отличается. Проекты, как правило, ограничены по сумме инвестиций. Даже если предполагается частичное рефинансирование проекта за счет доходов от какой-либо его части, предельные суммы вложений известны заранее. Следовательно, при бюджетировании ставится задача непревышения заданной суммы и возможной ее экономии.

Далее, при составлении бюджета проекта часто определяется только расходная составляющая (например, проект строительства завода, как правило, не предполагает детального определения доходов от производства, поскольку производство и сбыт - это уже другой проект).

Бюджет проекта могут использовать как инструмент управления кассой проекта, т. е. притоками и оттоками денежных средств, а не для управления бухгалтерской или управленческой прибылью. Иногда в качестве бюджета проекта используют бюджет движения денежных средств. Это некорректно, так как часть оборудования или персонала может закупаться или арендоваться - тогда возникает денежный отток. Однако частично могут привлекаться персонал и оборудование, уже имеющиеся в компании. Возникает схема внутренней аренды, при которой расчет деньгами не предусматривается, но если эти расходы не учесть, то будет недооценена затратная часть проекта.

Соответственно, при бюджетировании проекта не всегда уместно использовать стандартные бюджетные формы, такие как бюджет движения денежных средств или бюджет доходов и расходов. Можно предложить использовать специализированную форму бюджет инвестиционного проекта, который состоит из двух частей: денежной и неденежной (зачеты, внутренняя аренда, расчетный фонд оплаты труда привлекаемых на безвозмездной основе работников компании).

При составлении и исполнении бюджета проекта одним из возможных инструментов планирования и контроля является реестр проектных обязательств, который используется

\footnotetext{
${ }^{29}$ Грошева Надежда Борисовна, заместитель директора БМБШ по научной работе, зав. кафедрой финансового менеджмента БМБШ, канд. эконом. наук, доцент.
} 
для упорядочения документооборота, контроля цен, планирования бюджета (название и содержание формы разработаны автором). Под проектными обязательствами в данном случае понимаются все заказы на поставку товаров, работ, услуг для нужд проекта, которые в том числе принимают форму трудовых договоров, договоров аренды, договоров на закупку, служебных записок и распоряжений и т. д. Кроме того, к проектным обязательствам следует отнести всю внутреннюю аренду - привлечение имеющегося у компании оборудования, помещений, персонала.

Проектные обязательства формируются после составления структуры декомпозиции работ и анализа необходимых для выполнения каждой из них ресурсов. Проектные обязательства формализуют процедуры получения ресурсов (закупку, аренду и т д.).

При составлении матрицы ответственности и анализа персонала, который не входит в команду проекта, но привлекается для выполнения определенных работ, процедура заказа или бронирования персонала также инициирует проектное обязательство.

Проектные обязательства имеют следующие обязательные признаки:

1) наименование и код ресурса;

2) количество ресурса;

3) прогнозируемая цена ресурса;

4) дата привлечения (начало привлечения и срок привлечения);

5) прогнозируемый порядок расчетов.

C помощью реестра можно укрупнить заказ на поставку материалов, например объединив закупку однотипных или одинаковых ресурсов в один раздел реестра.

Соответственно реестр может быть разделен по видам потребностей - товары, работы, услуги. В свою очередь товары можно разделить на оборудование, расходные материалы, сырье, полуфабрикаты и т. д.

Реестр составляется на весь срок проекта, включает обязательства по всем работам. Для детализации расходов по годам или кварталам используются бюджетные формы соответствующей периодичности.

Реестр проектных обязательств позволяет в числе прочего отслеживать цены на закупаемые ресурсы. При изменении цен в реестр могут быть внесены изменения.

Целесообразно разработать регламент составления и ведения реестра. В регламенте в числе прочего следует отразить порядок внесения изменений в реестр. Изменения могут быть вызваны внутренними и внешними относительно проекта причинами.

Например, изменение технологии выполнения работы или выявление оптимального для использования материала - это внутренние изменения. Их внесение следует обосновать и указать их влияние на все части проекта, так как, например, при замене используемого для возведения внутренних перегородок в здании кирпича на монолитный пенобетон или сэндвич-панели поменяется технология строительства перегородок, потребуются строители с другими навыками, может измениться система звукоизоляции и пр. Соответственно на основании описания затрагиваемых частей проекта изменятся разделы реестра проектных обязательств (далее - РПО).

Внешние изменения могут быть вызваны, например, колебанием цен в результате повышения таможенных пошлин, конъюнктуры цен на нефть и так далее. При внесении подобных корректировок прилагается пояснительная записка со ссылкой на соответствующие основания. Изменение цен повлияет на РПО и соответственно бюджет проекта.

При переложении в бюджетные показатели РПО следует учесть точку и объем заказа денежных средств под конкретное обязательство (например, при заказе оборудования под индивидуальный заказ необходимо внести аванс, составляющий определенный процент от стоимости оборудования до начала его изготовления) или при оформлении в собственность земельного участка часть суммы депонируется на эскро-счетах.

Реестр проектных обязательств, кроме того, помогает учесть все суммы, необходимые для оплаты, при смещении графика выполнения проекта (бывают ситуации, когда при 
изменении сроков выполнения работ и переносе следующих работ соответствующие суммы оплаты в бюджете не сдвигаются и к моменту оплаты необходимой суммы не хватает).

При привлечении заемных средств на возвратной основе в бюджете в отдельном разделе должны быть отражены даты возврата основной суммы и даты уплаты процентов.

После составления реестра цифры расходов попадают в соответствующие разделы бюджета проекта, а под потребность в закупке проводятся тендеры или заключаются договора в установленном для проекта порядке.

Дополнительно после заключения контрактов составляется реестр договоров. В реестре будет отражена информация о контрагентах, даты и условия оплаты и поставки. Реестр договоров и РПО будут отличаться на суммы внутренней аренды, поскольку, как правило, внутреннее привлечение ресурсов договором не оформляется.

Из реестра договоров и проектных обязательств вытекает кассовый план, т. е. план платежей на текущий период (неделю, месяц, квартал). Задача кассового плана сбалансировать денежные поступления и платежи. В кассовом плане в разделе «Поступления» будут отражены средства из всех источников - в том числе займы и кредиты, и поступления, которые генерирует собственно проект.

Соответственно, сумма кассовых планов за период должна быть равна денежной части бюджета проекта.

Все неденежные операции должны быть отражены в бюджете в специальном разделе.

Есть мнение, что при управлении инновационными проектами жесткое планирование невозможно. Однако если составлен примерный перечень (структура декомпозиции) работ, то определить базовые ресурсы для их исполнения не составит труда.

Важным вопросом является схема выплаты вознаграждения команде проекта. Идеальным вариантом являлась бы реализация проекта полностью за счет исполнителя и чтобы компенсация расходов и оплата работы исполнителя проводились бы только после завершения проекта. Однако такая схема практически невозможна из-за нежелания исполнителя принимать на себя все риски проекта или отсутствия у него возможностей для финансирования.

Следовательно, необходимо финансировать проект за счет заказчика (или инвестора), выделяя соответствующие средства исполнителю (или подрядчику) на выполнение собственно работ проекта и вознаграждение исполнителя. Возникает проблема расчета сумм к оплате.

Рассмотрим схему финансирования на примере любого проекта, где есть заказчик и исполнитель. Предположим, имеется заказчик (скажем, собственник земельного участка, имеющий личные средства для строительства) и исполнитель (генподрядчик). На первый взгляд схема финансирования довольно проста: есть смета расходов на строительство и расчетное вознаграждение генподрядчику, обычно в процентах от сметы. Однако существует несколько проблемных моментов.

1. Смета часто достаточно приблизительная, и у подрядчика может возникнуть искушение завысить смету для получения пропорционально большего вознаграждения.

2. Смета часто составляется пообъектно, не разбивается на периоды времени, и трудно оценить, в какой момент какую сумму надо оплатить.

3. При привязке вознаграждения подрядчика к расходам по смете может возникнуть ситуация, когда подрядчик инициирует проведение большей части расходов в начале проекта, чтобы получить вознаграждение уже в начале работ.

4. Если вознаграждение будет рассчитано как определенная сумма в день (месяц, квартал), подрядчик может осознанно затягивать срок выполнения проекта.

Часто для оценки степени выполнения проекта (и соответственно доли выплачиваемого вознаграждения) используют анализ проекта по освоенному объему.

Суть этого метода заключается в привязке расходов к объему выполненных работ и периодам времени. Для использования анализа по освоенному объему следует определить: 
1) составляющие стоимости работы (можно использовать данные 5М-анализа натуральные и денежные показатели);

2) период выполнения каждой работы (исходя из календарного плана работ);

3) бюджет работ (по данному объекту);

4) расходы в единицу времени;

5) отклонение стоимости работ;

6) провести анализ причин отклонений.

Далее определяются следующие показатели:

1) полная плановая стоимость объекта (ППСО);

2) плановое время выполнения работы (ПВВР);

3) плановая стоимость выполнения работы (ПСВР);

4) фактическая стоимость завершенных работ (ФСЗР);

5) плановая стоимость завершенных работ (ПСЗР).

Очевидно, что ППСО равна сумма всех ПСВР.

ПСЗР определяется исходя из плановой стоимости тех работ, которые были выполнены на конкретный момент времени. ФСЗР определяется исходя из фактически потраченных на завершенные работы средств.

Следует учесть, что при расчете данных показателей мы используем не денежный поток, а именно затраты на работы. Так, например, иногда покупается большой запас стройматериалов на несколько работ (для снижения стоимости закупки, упрощения логистики и пр.). Но для расчета фактической стоимости мы определим затраты на те материалы, которые были использованы для данной работы.

Приведем пример.

Проведение некоторой работы требует определенного количества материалов А, Б и В:

Таблица 1

\begin{tabular}{|l|l|l|l|}
\hline Вид материала & $\begin{array}{l}\text { Плановый расход } \\
(П Р)\end{array}$ & $\begin{array}{l}\text { Плановая стоимость } \\
\text { единицы (ПСЕ), руб. }\end{array}$ & $\begin{array}{l}\text { Плановые затраты на } \\
\text { материал = ПР*ПСЕ } \\
\text { руб. }\end{array}$ \\
\hline А & 10 & 100 & 1000 \\
\hline Б & 20 & 150 & 3000 \\
\hline В & 25 & 50 & 1000 \\
\hline Итого & & & 5000 \\
\hline
\end{tabular}

Очевидно, что итог подводится только по плановым затратам на материал по данной работе. Сумма плановых затрат на материал составит ППСО.

Предположим, что закуплено следующее количество материала по следующим ценам:

Таблица 2

\begin{tabular}{|l|l|l|l|}
\hline Вид материала & Закуплено & $\begin{array}{l}\text { Фактическая } \\
\text { стоимость единицы } \\
(Ф С Е), \text { руб. }\end{array}$ & $\begin{array}{l}\text { Денежный поток = } \\
\text { фактически } \\
\text { закуплено *ФСЕ } \\
\text { руб. }\end{array}$ \\
\hline А & 20 & 80 & 1600 \\
\hline Б & 25 & 90 & 2250 \\
\hline В & 30 & 45 & 1350 \\
\hline Итого & & 5200 \\
\hline
\end{tabular}

Однако для выполнения работы использовано не плановой количество материалов, а, например, следующее (при этом работа выполнена полностью и с требуемым качеством): 


\begin{tabular}{|l|l|}
\hline Вид материала & Использовано \\
\hline А & 10 \\
\hline Б & 17 \\
\hline В & 27 \\
\hline
\end{tabular}

Тогда ФСЗР составит:

Таблица 4

\begin{tabular}{|l|l|l|l|}
\hline Вид материала & $\begin{array}{l}\text { Фактически } \\
\text { потрачено (ФП) }\end{array}$ & $\begin{array}{l}\text { Фактическая } \\
\text { стоимость единицы } \\
\text { (ФСЕ), руб. }\end{array}$ & $\begin{array}{l}\text { Фактические } \\
\text { расходы на } \\
\text { материалы = ФП } \\
\text { *ФЕ, руб. }\end{array}$ \\
\hline А & 10 & 80 & 800 \\
\hline Б & 17 & 90 & 1530 \\
\hline В & 27 & 45 & 1215 \\
\hline Итого & \multicolumn{2}{|l|}{} \\
\hline
\end{tabular}

Таким образом, ФСЗР меньше ППСО, но это не означает, что выполнено меньше работ. Работы выполнены полностью, но они обошлись дешевле плановой стоимости.

Следует оценить, какие факторы повлияли на снижение стоимости работ: экономия на количестве материалов или снижение их стоимости (вполне возможно, что было израсходовано больше материалов, чем планировалось, и тогда при повышении стоимости материалов проект может обойтись дороже, чем планировалось).

Если повышение цены вызвано внешними факторами, то возникают дополнительные расходы заказчика, но при этом вознаграждение подрядчика считается от плановой цены.

Соответственно, при получении экономии на материалах вознаграждение подрядчика можно привязать к плановой стоимости выполнения работ, так как подрядчик в результате снизил для заказчика стоимость проекта. Если увеличение количества израсходованных материалов было вызвано объективными факторами и не зависело от подрядчика, то его вознаграждение можно рассчитывать от фактических расходов материала.

Для оценки стоимости проекта с учетом изменений цен или расходов можно оценить динамику изменений каждого фактора (цен и объема расходов) по уже выполненным работам и внести соответствующие изменения в реестр проектных обязательств.

Реестр проектных обязательств можно использовать для мониторинга уровня цен на закупаемые ресурсы, для укрупнения закупки (путем сбора однотипных ресурсов в один раздел реестра), внесения изменений в бюджет проекта, оценки возможности закупки ресурсов извне при наличии у компании аналогичного внутреннего ресурса.

Таким образом, автор предлагает использовать для планирования финансов проекта и управления ими дополнительную форму - реестр проектных обязательств, дополняющий основные бюджетные формы. Реестр позволяет отслеживать все затраты проекта, в том числе и произведенные в неденежной форме. Кроме того, с помощью РПО появляется возможность контроля и анализа изменений в объеме и цене закупки ресурсов и своевременного внесения изменений в бюджеты. Реестр проектных обязательств также может быть использован для изменения сроков платежей в зависимости от даты начала выполнения работ. 